\title{
Lipodystrophy syndrome in HIV-infected patients - a cohort study in Lower Silesia, Poland
}

\author{
Justyna Drelichowska ${ }^{1,2}$, Wiesława Kwiatkowska ${ }^{1,2}$, Brygida Knysz $^{1,3}$, Katarzyna Arczyńska ${ }^{1}$, \\ Marcin Czarnecki ${ }^{1,3}$, Jacek Gąsiorowski ${ }^{1,3}$, Maciej Karczewski ${ }^{1}$, Wojciech Witkiewicz ${ }^{1,2}$
}

${ }^{1}$ Wrovasc - Integrated Cardiovascular Centre, Regional Specialist Hospital, Research and Development Center in Wroclaw, Wroclaw, Poland

${ }^{2}$ Department of Angiology, Regional Specialist Hospital in Wroclaw, Research and Development Center in Wroclaw, Wroclaw, Poland

${ }^{3}$ Department of Infectious Diseases, Wroclaw Medical University, Wroclaw, Poland

\begin{abstract}
Introduction: Human immunodeficiency virus (HIV)-associated lipodystrophy syndrome (LS) is defined as a redistribution of adipose tissue, metabolic and endocrine abnormalities, resulting from combined antiretroviral therapy (cART). Aim of this study was to evaluate LS in HIV-infected patients from Lower Silesia, Poland.

Material and methods: One hundred and ten HIV-infected patients on CART for at leat 2 years were included. Two subgroups of patients were established: patients with no or slight symptoms of lipodystrophy - LS1; and patients with moderate and severe changes - LS2. The patients were also divided according to the type of LS: lipoatrophy, lipoaccumulation, both lipoatrophy and lipohypertrophy.

Results: LS2 subgroup was significantly older, had much lower body weight, lower WHR, more advanced atherosclerotic changes. Patients with advanced lipodystrophy syndrome had very high packyear values. LS1 group had hypertension much more frequently than controls. Comparing with controls, LS2 had significantly lower low-density lipoprotein (LDL) cholesterol, higher triglyceride levels, longer time of HIV infection, longer time of cART and cumulative time on cART (including PIs and NRTIs). A higher current CD4+ T-lymphocyte count and more frequent HCV infection in patients with more severe adipose tissue changes were of little statistical significance. Fat loss of face, limbs, buttocks and together with lipoaccumulation of abdomen were most common.

Conclusions: Lipodystrophy syndrome is still observed in the vast majority of HIV-positive patients receiving antiretroviral therapy, especially those older and with longer time of cumulative NRTI and PI treatment. A great concern is needed to evaluate body composition and risk factors for metabolic changes to prevent their progression and healthy consequences.
\end{abstract}

HIV AIDS Rev 2017; 16: 40-49 DOI: https://doi.org/10.5114/hivar.2017.65114

Key words: HIV, antiretroviral therapy, lipodystrophy syndrome, metabolic abnormalities.

Address for correspondence: Brygida Knysz, Department of Infectious Diseases, Wroclaw Medical University, 5 Koszarowa St., 51-149 Wroclaw, Poland, e-mail: brygida.knysz@gmail.com
Article history

Received: 11.07.2016

Received in revised form: 20.10 .2016

Accepted: 31.10 .2016

Available online: 20.01 .2017 


\section{Introduction}

Human immunodeficiency virus (HIV)-associated lipodystrophy syndrome (LS) is defined as a redistribution of adipose tissue accompanied by metabolic and endocrine abnormalities, resulting from combined antiretroviral therapy (cART) [1-5].

The term was first used in 1998 by Andrew Carr et al. to describe morphological and metabolic abnormalities observed in HIV-infected patients treated with protease inhibitors (PIs) [2]. However, further studies also discovered the influence of other antiretroviral drugs, mostly nucleoside reverse transcriptase inhibitors (NRTIs), and of HIV infection itself [6-11]. Most authors emphasize the significant role of adipose tissue in pathogenesis of this condition; the role of the immune system, proinflammatory cytokines such as TNF- $\alpha$ and interleukin (IL)- 6 and genetic predisposition are also mentioned $[2,3,8,12,13]$.

The morphological abnormalities observed in clinical presentation of patients with LS include: lipoatrophy (loss of subcutaneous adipose tissue in the face, limbs, and buttocks), isolated or accompanied by lipoaccumulation (growth of adipose tissue in the abdomen, waist, neck and growth of visceral adipose tissue) [14-19].

Lipoatrophy should be distinguished from cachexia and malnutrition observed in advanced stages of AIDS and chronic infections accompanying HIV infection. Therapy with PI is considered by many authors as an independent risk factor for the development of insulin resistance, abnormal glucose tolerance and diabetes mellitus type 2 [20-24]. Other metabolic abnormalities include: increased triglyceride concen- tration, low-density lipoprotein (LDL) and very-low-density lipoprotein (VLDL) cholesterol and apolipoproteins B and E levels, lower high-density lipoprotein (HDL) cholesterol level [25-27].

The aim of this study was to evaluate the lipodystrophy syndrome in HIV-infected patients living in Lower Silesia, Poland.

\section{Material and methods}

\section{Material}

One hundred and ten HIV-infected patients, treated in the Acquired Immunodeficiency Syndrome Outpatient Clinic in Wroclaw were included in the observational study. The same study population was analyzed in our previous publications [28]. The preliminary inclusion criteria were: documented HIV infection and antiretroviral therapy, of no less than 2 years. The exclusion criteria were: AIDS diagnosis, acute medical condition (fever, severe infection, inflammation), serum creatinine level over $2 \mathrm{mg} \%$ and over fivefold increase in the alanine aminotransferase level, body mass index $(\mathrm{BMI})>30 \mathrm{~kg} / \mathrm{m}^{2}$, age over 65 years old, diabetes, treatment with such drugs as metphormin. The following patient data were known at the beginning of the study: current virological and immune status, history of the infection and information about coinfection with hepatitis $B$ and/or hepatitis $\mathrm{C}$ virus (Table 1).

All patients were on antiretroviral treatment for 2-8 years, 4 years on average. The time of cumulative antiretroviral treatment with medications from all antiretroviral classes

Table 1. Virological and immunological characteristics of patients on antiretroviral therapy

\begin{tabular}{|c|c|}
\hline Infection data & Results \\
\hline Mode of transmission HET/IDU/MSM, $n$ [\%] & $31 / 51 / 28(28.2 / 46.4 / 25.5)$ \\
\hline Time of HIV infection [years] $^{\star}$ & $8(3.4-12.0)$ \\
\hline AIDS, $n[\%]$ & $32(29.1)$ \\
\hline HCV infection, $n[\%]$ & $59(53.6)$ \\
\hline HBV infection, $n[\%]$ & $26(23.6)$ \\
\hline CD4+ T-lymphocytes [cells/ $\mu$ l] $]^{*}$ & $515(388-693)$ \\
\hline CD4+ T-lymphocyte nadir $\left[\right.$ cells/ $\mu$ l] ${ }^{\star}$ & $200(66-280)$ \\
\hline $\log _{10}$ HIV RNA at the moment of test [copies $\left./ \mathrm{ml}\right]^{*}$ & $1.7(1.6-1.7)$ \\
\hline HIV RNA below the sensitivity of the method, $n$ [\%] & $93(84.5 \%)$ \\
\hline $\log _{10}$ HIV RNA zenith, copies $/ \mathrm{ml}, n=84^{*}$ & $4.7(3.6-5.3)$ \\
\hline CART & Results \\
\hline Time of ARV treatment [years] ${ }^{*}$ & $4(2-8)$ \\
\hline 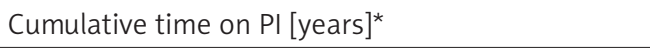 & $3.79(0.71-7.37)$ \\
\hline Cumulative time on NNRTI [years] ${ }^{*}$ & $0(0-1.6)$ \\
\hline Cumulative time on NRTI [years] $^{*}$ & $8.79(4.03-13.98)$ \\
\hline Cumulative time on CART [years] $^{\star}$ & $16.6(8.13-24.97)$ \\
\hline
\end{tabular}

*Median, IQR, $n$ (\%) - absolute number (percentage), other data-arithmetic mean

HET - heterosexual contacts, IDU - intravenous drug users, MSM - men who have sex with men 
Table 2. Characteristics of the study group (SG) and control group (CG)

\begin{tabular}{|c|c|c|c|}
\hline Feature & SG, $n=110$ & CG, $n=42$ & $p$-value \\
\hline Age [years] $(\mathrm{a}, \mathrm{sd})$ & $39.8 \pm 9.3(20-62)$ & $41 \pm 11.5(20-58)$ & 0.48 \\
\hline Sex (male), $n$ [\%] & $70(63.6)$ & $26(61.9)$ & 0.99 \\
\hline $\mathrm{BMI}^{*}$ & $22.86(21-25)$ & $25.6(24-27)$ & 0.0001 \\
\hline Waist $[\mathrm{cm}]^{*}$ & $82.75(76.5-91.0)$ & $86.75(75-95)$ & - \\
\hline Hips $[\mathrm{cm}]^{*}$ & $94(88-98)$ & $100(95-105)$ & - \\
\hline WHR* & $0.9(0.84-0.96)$ & $0.89(0.78-0.94)$ & 0.055 \\
\hline Smokers, $n[\%]$ & $46(84.6)$ & $28(47.6)$ & 0.0001 \\
\hline Pack-years* & $18(8.875-27.125)$ & $13.375(4-27.5)$ & 0.33 \\
\hline $\mathrm{cIMT}[\mathrm{mm}]^{*}$ & $0.66(0.58-0.78)$ & $0.54(0.46-0.62)$ & 0.0001 \\
\hline cIMT mean-max $[\mathrm{mm}]^{*}$ & $0.99(0.84-1.18)$ & $0.81(0.67-0.99)$ & 0.0001 \\
\hline Atherosclerotic plaques, $n$ [\%] & $35(31.8)$ & $7(16.7)$ & 0.12 \\
\hline Hypertension, $n$ [\%] & $49(44.5)$ & $10(23.8)$ & 0.039 \\
\hline $\mathrm{TC}[\mathrm{mg} / \mathrm{dl}](\mathrm{a}, \mathrm{sd})$ & $195.3 \pm 45.4$ & $212.67 \pm 38.7$ & 0.03 \\
\hline Non-HDL [mg/dl] & $139.2 \pm 42.4$ & $150.41 \pm 35.7$ & 0.13 \\
\hline $\mathrm{LDL}[\mathrm{mg} / \mathrm{dl}](\mathrm{a}, \mathrm{sd})$ & $110.13 \pm 38.1$ & $126.34 \pm 31.7$ & 0.016 \\
\hline $\mathrm{HDL}[\mathrm{mg} / \mathrm{dl}]^{*}$ & $51(40-64)$ & $58.5(47-71)$ & 0.012 \\
\hline TG $[\mathrm{mg} / \mathrm{dl}]^{*}$ & $131.5(93-189)$ & $100.5(68-137)$ & 0.0077 \\
\hline Fasting glucose $[\mathrm{mg} \%]^{\star}$ & $91(86.0-96.5)$ & $93.5(87-101)$ & 0.11 \\
\hline Insulin $[\mathrm{Ul} / \mathrm{ml}]^{*}$ & $7.15(5.2-10.4)$ & $7(4.4-10.9)$ & 0.64 \\
\hline HOMA-IR $R^{\star, \star *}$ & $1.63(1.1-2.23)$ & $1.48(0.98-2.67)$ & 0.9 \\
\hline Insulin resistance, $n$ [\%] & $21(19.4)$ & $11(27.5)$ & 0.55 \\
\hline $\mathrm{CRP}\left[\mathrm{mg} / \mathrm{l}^{*}\right.$ & $0.62(0.19-1.53)$ & $0.72(0.19-1.52)$ & 0.89 \\
\hline Fibrinogen $[\mathrm{g} / \mathrm{l}]^{*}$ & $2.7(2.3-3.2)$ & $2.9(2.6-3.3)$ & 0.037 \\
\hline D-dimers $[\mathrm{ng} / \mathrm{ml}]^{*}$ & $216.6(169-319)$ & $245.7(170-349)$ & 0.78 \\
\hline Positive family history, $n$ [\%] & $35(31.8)$ & $5(11.9)$ & 0.022 \\
\hline Metabolic syndrome, $n$ [\%] & $22(20)$ & $5(11.9)$ & 0.35 \\
\hline Diabetes, $n$ [\%] & $3(2.7)$ & $0(0)$ & 0.66 \\
\hline Obesity/overweight/underweight, $n$ [\%] & $6 / 21 / 7(5.5 / 19.1 / 6.3)$ & $5 / 23 / 0(12 / 54.8 / 0)$ & 0.0001 \\
\hline Cardiovascular disease risk factors, $n[\%]$ & $3(2.7)$ & - & - \\
\hline CV - ATP III risk & $2(1-6)$ & $2(1-5)$ & 0.38 \\
\hline
\end{tabular}

${ }^{*}$ Median, IQR, $n$ (\%) - absolute number (percentage), other data-arithmetic mean

${ }^{* *}$ Homeostatic Model Assessment of Insulin Resistance

${ }^{* * *}$ Cardio-vascular risk according Adult Treatment Panel III

was from about 8 to 25 years, 16.6 years on average; the longest cumulative time of treatment concerned NRTI. We did not analyze contribution of certain antiretroviral drugs and their classes in the LS. Before the beginning of this study there were changes in the cART in many patients because of drug toxicity and viral failure.

The control group included 42 healthy individuals living in Lower Silesia, matched for age and sex with the patients, with negative medical history of chronic diseases and cardiovascular disease events (Table 2).

Characteristics of the study group (SG) and control group (CG) are presented in Table 2.

\section{Methods}

The study protocol included collecting anamnesis and data from medical documentation, especially information about HIV infection and antiretroviral treatment (in years and cumulative treatment with NNRTI, NRTI, PI). Physical examination was performed with particular emphasis on anthropometric measurements - weight, height, waist and hip circumferences, BMI and waist-hip ratio (WHR). The evaluation of clinical features of LS was carried out using the methodology of HIV Outpatient Study (HOPS), a multi-site clinical study of over 4800 patients receiving ambulatory care in the USA in 1992-1998 [18]. 
The LS features were evaluated by two physicians - researchers, taking into consideration patients' opinions. The physical examination included evaluation of upper and lower limbs, buttocks, hips and face regarding fat loss and of visceral regions, trunk and neck with regard to fat accumulation. The researchers graded all the changes from 0 points (absent) to 3 points (the most severe). The maximum possible score was 15 points.

The quantitative parameter for lipodystrophy was used for analyzing dependencies between lipodystrophy and atherosclerosis. All changes were classified in a four-degree scale reflecting the severity of lipodystrophy syndrome: no LS symptoms, subtle changes - noticeable only if specifically looked for, with no change in clothing fit (up to 3 points), moderate changes - easily noted by the patient or physician, often requiring a change in clothing size (3-7 points), severe changes obvious to the casual observer, requiring a change in clothing size (over 7 points) (Figure 1).

Following the HOPS method, two main subgroups of patients were established:

1) patients with no or slight symptoms of lipodystrophy (57 individuals) - LS1,

2) patients with moderate and severe changes (53 individuals) - LS2

The purpose of this division was to compare their virological, immunological and clinical state and to evaluate the data concerning cART in both subgroups. The patients were also divided according to the type of lipodystrophic changes, into the following subgroups: lipoatrophy $(n=34)$, lipoaccumulation $(n=14)$, mixed forms - features of both lipoatrophic and lipohypertrophic changes $(n=46)$. In the control group, no features of lipoatrophic or mixed lipodystrophic changes were observed; 15 controls had symptoms of visceral obesity.

In all patients, a duplex ultrasound of carotid was performed in order to evaluate subclinical atherosclerosis by means of computer-measured cIMT. Carotid ultrasound was performed using a high-resolution ultrasound GE LOGIQ 7 GE with broadband linear probe 6-12 MHz. The main parameters for each patient were cIMT (the average IMT value obtained for all the series) and IMT meanmax (defined as the average of 12 maximal IMT measurements from each projection) [29].

\section{Statistical analysis}

Quantitative variables were presented as an arithmetic mean, geometric mean or median, depending on normality of distribution. To achieve normality, the logarithmic transform was applied to the variable elements. For each estimator, 95\% confidence intervals were calculated. Qualitative variables are presented as the number of patients in each group. Differences in quantitative features between groups were analyzed by Student's $t$-test, the Mann-Whitney test or Kruskal-Wallis wit post-hoc analysis. Differences in the qualitative features were analyzed using the $\chi^{2}$ test or Fisher's exact test (for small groups). The effect of clinical

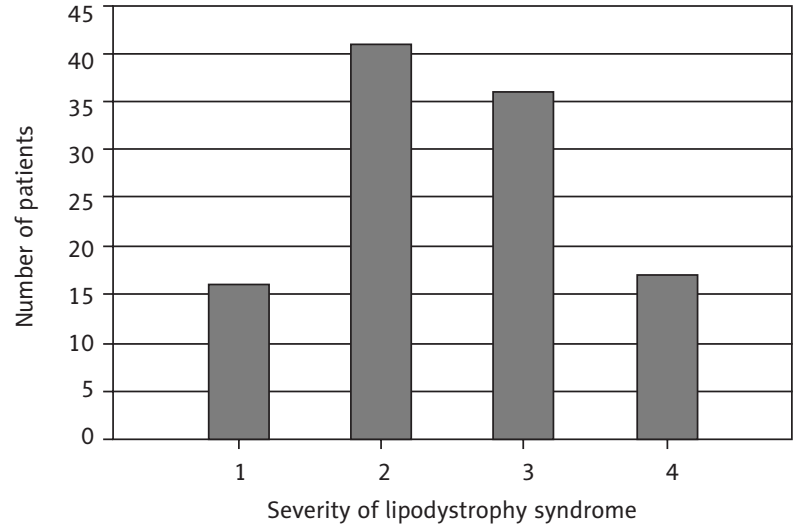

Figure 1. Classification of patients according to the severity of lipodystrophy syndrome

features on lipodystrophy was assessed using logistic regression. The analysis was made using $\mathrm{R}$ and MedCalc statistical packages. All results with a significance level $p<0.05$ were found significant.

The study was conducted with the approval of the Bioethics Committee. All participants provided their written informed consent to participate in the study, according to the Helsinki Declaration.

\section{Results}

At the beginning of the study, the patients were classified according to the severity of lipodystrophy syndrome, from no LS symptoms to severe changes in adipose tissue distribution. The subgroups with subtle and moderate changes were the most numerous (Figure 1).

Table 3 presents and compares the characteristics of both subgroups. The patients from LS2 subgroup were significantly older, had much lower body weight and smaller hip circumference and, as a result, lower WHR.

Patients from LS2 subgroup had noticeably more advanced atherosclerotic changes, expressed by higher cIMT values. Both LS1 and LS2 patients had significantly higher IMT mean-max values in comparison with the control group. Among traditional risk factors, there was a noticeable difference concerning smoking. Patients with advanced lipodystrophy syndrome had very high pack-year values. After further post-hoc analysis of subgroups and the control group, it was discovered that LS1 had hypertension much more frequently than controls (0.033). In comparison with the control group, LS2 had significantly lower LDL cholesterol and higher triglyceride values $(p=0.015, p=0.028$ respectively). No other statistically significant differences in basic laboratory parameters or concerning cardiovascular disease risk factors were observed (Table 3 ).

Patients in LS2 subgroup had noticeably longer documented time of HIV infection (Table 4). General time of cART and cumulative time on antiretroviral drugs, including cumulative time on PIs and cumulative time on 
Table 3. Clinical and laboratory characteristics of patients from subgroups LS1 and LS2

\begin{tabular}{|c|c|c|c|}
\hline Feature & LS1, $n=57$ & LS2, $n=53$ & $p$-value \\
\hline Age [years] $(a, s d)$ & $39(31.75-43)$ & $42(35-48)$ & 0.048 \\
\hline Sex (male), $n[\%]$ & $33(57.9)$ & $37(69.8)$ & 0.38 \\
\hline $\mathrm{BMI}^{*}$ & $23.9(21.6-25.7)$ & $22(20.6-24.0)$ & 0.015 \\
\hline Waist $[\mathrm{cm}]^{*}$ & $81(75.6-90.0)$ & $84(79.0-91.5)$ & 0.29 \\
\hline Hips $[\mathrm{cm}]^{\star}$ & $95(90-100)$ & $90.5(87-95)$ & 0.014 \\
\hline $\mathrm{WHR}^{*}$ & $0.88(0.80-0.94)$ & $0.93(0.88-1.00)$ & 0.0024 \\
\hline $\mathrm{cIMT}[\mathrm{mm}]^{*}$ & $0.64(0.56-0.76)$ & $0.71(0.61-0.82)$ & 0.026 \\
\hline cIMT mean-max $[\mathrm{mm}]^{*}$ & $0.93(0.83-1.12)$ & $1.06(0.90-1.21)$ & 0.076 \\
\hline Atherosclerotic plaques, $n$ [\%] & $15(26.3)$ & $20(37.7)$ & 0.28 \\
\hline Smokers, $n[\%]$ & $45(79.0)$ & $48(90.6)$ & 0.18 \\
\hline Pack-years* & $12(5.75-21.50)$ & $23.375(13.3-29.5)$ & 0.0017 \\
\hline Hypertension, $n$ [\%] & $28(50.9)$ & $20(37.7)$ & 0.23 \\
\hline $\mathrm{TC}[\mathrm{mg} / \mathrm{dl}](\mathrm{a}, \mathrm{sd})$ & $204(164-226)$ & $187(156-223)$ & 0.82 \\
\hline Non HDL-C [mg/dl] & $143(105-168.75)$ & $128(100.75-166)$ & 0.71 \\
\hline LDL-C [mg/dl] $(\mathrm{a}, \mathrm{sd})$ & $114(82.75-145.75)$ & $101.8(80.00-124.5)$ & 0.36 \\
\hline $\mathrm{HDL}-\mathrm{C}[\mathrm{mg} / \mathrm{dll}]^{*}$ & $53(40-62)$ & $49(40.5-68.0)$ & 0.75 \\
\hline $\mathrm{TG}[\mathrm{mg} / \mathrm{dll}]^{*}$ & $131(95.25-183.25)$ & $132(91.50-196.75)$ & 0.75 \\
\hline Fasting glucose [mg\%]* & $91(86.00-97.53)$ & $91(85.75-96.00)$ & 0.71 \\
\hline Insulin $[\mathrm{IU} / \mathrm{ml}]^{*}$ & $6.7(5.45-8.93)$ & $7.8(4.80-11.43)$ & 0.15 \\
\hline HOMA-IR*,** & $1.46(1.14-1.91)$ & $1.91(1.08-2.59)$ & 0.13 \\
\hline Insulin resistance, $n[\%]$ & $7(12.7)$ & $14(26.4)$ & 0.18 \\
\hline $\mathrm{CRP}[\mathrm{mg} / \mathrm{l}]^{*}$ & $0.47(0.18-1.40)$ & $0.89(0.2-2)$ & 0.13 \\
\hline Fibrinogen $[\mathrm{g} / \mathrm{l}]^{*}$ & $2.61(2.3-3.1)$ & $2.71(2.28-3.40)$ & 0.47 \\
\hline D-dimers $[\mathrm{ng} / \mathrm{ml}]^{*}$ & $201.8(169.0-316.0)$ & $253.2(171.9-331.0)$ & 0.18 \\
\hline Positive family history, $n$ [\%] & $18(31.6)$ & $17(32.1)$ & 0.89 \\
\hline Metabolic syndrome, $n$ [\%] & $12(21.1)$ & $10(18.9)$ & 0.96 \\
\hline Diabetes, $n$ [\%] & $1(1.8)$ & $2(3.8)$ & 0.94 \\
\hline Obesity/overweight/underweight, $n$ [\%] & $5 / 11 / 5(8.8 / 19.3 / 8.8)$ & $1 / 10 / 4(1.9 / 18.9 / 7.5)$ & 0.43 \\
\hline Cardiovascular disease risk factors, $n[\%]$ & $0(0)$ & $3(5.7)$ & 0.23 \\
\hline CV - ATP III risk ${ }^{*, * * *}$ & $2(1-6)$ & $2(1-8)$ & 0.45 \\
\hline
\end{tabular}

*Median, IQR, $n$ (\%) - absolute number (percentage), other data-arithmetic mean

${ }^{* *}$ Homeostatic Model Assessment of Insulin Resistance

${ }^{* * *}$ Cardio-vascular risk according Adult Treatment Panel III

NRTIs, were significantly longer in LS2. Some interesting findings of little statistical significance indicate a higher current CD4+ T-lymphocyte count and more frequent $\mathrm{HCV}$ infection in patients with more severe adipose tissue changes.

Various combinations of fat distribution abnormalities were observed in LS patients. The most common one was cumulative fat loss in areas of the face, limbs, waist and hips (lipoatrophy); another frequent pattern was lipoatrophy combined with lipoaccumulation in the visceral area (mixed lipodystrophy). The percentages of particular combinations are presented in Figure 2.
Within the whole group, all types of dystrophic changes were observed: lipoatrophy (30.9\%), lipoaccumulation (12.7\%) and, most frequently, mixed forms (41.7\%). Figure 3 shows numbers of patients in specific subgroups, according to various dystrophic changes.

Table 5 presents statistically significant differences observed in patients with different types of lipodystrophy. There were significant differences between the subgroups, concerning anthropometric measurements: BMI and waist circumference were noticeably higher in lipoaccumulation and mixed subgroups than in the lipoatrophy group; hip circumference was significantly lower in the atrophy 
Table 4. Infection characteristics in subgroups LS1 and LS2

\begin{tabular}{|c|c|c|c|}
\hline Infection data & LS1 & LS2 & $p$-value \\
\hline Mode of transmission HET/IDU/MSM ${ }^{* \star}, n[\%]$ & $\begin{array}{c}16 / 24 / 17 \\
(28.1 / 42.1 / 29.8)\end{array}$ & $\begin{array}{c}15 / 27 / 11 \\
(28.3 / 50.9 / 20.8)\end{array}$ & 0.51 \\
\hline Time of HIV infection [years] ${ }^{*}$ & $4.5(2.5-9.0)$ & $11(5.75-17.00)$ & 0.0003 \\
\hline AIDS, $n[\%]$ & $15(26.3)$ & $17(32.1)$ & 0.65 \\
\hline HCV infection, $n$ [\%] & $25(43.9)$ & $34(64.2)$ & 0.071 \\
\hline HBV infection, $n[\%]$ & $11(19.3)$ & $15(28.3)$ & 0.37 \\
\hline CD4+ T-lymphocytes [cells/ $\mu$ l] ${ }^{*}$ & $488(386.5-632.25)$ & $609(400.75-760.25)$ & 0.053 \\
\hline CD4+ T-lymphocyte nadir [cells/ $\mu$ l] ${ }^{*}$ & $200(49.00-267.75)$ & $198(77.25-293.00)$ & 0.68 \\
\hline $\log _{10}$ HIV RNA at the moment of test [copies/ml] ${ }^{*}$ & $1.69(1.6-1.7)$ & $1.6(1.6-1.7)$ & 0.28 \\
\hline HIV RNA below the sensitivity of the method, $n$ [\%] & $45(78.9)$ & $48(90.6)$ & 0.21 \\
\hline $\log _{10}$ HIV RNA zenith, copies/ml* $(n=84)$ & $4.27(3.31-5.13)$ & $4.93(4.06-5.38)$ & 0.14 \\
\hline CART & LS1 & LS2 & $p$-value \\
\hline Time of cART [years] $^{\star}$ & $3(1-7)$ & $6(3-10)$ & 0.0007 \\
\hline Cumulative time on PI [years] $^{\star}$ & $2.25(0.10-5.67)$ & $5.27(2.14-8.44)$ & 0.01 \\
\hline Cumulative time on NNRTI [years] $^{*}$ & $0(0-1.3)$ & $0(0-2.65)$ & 0.42 \\
\hline Cumulative time on NRTI [years] $^{*}$ & $6.22(2.3-11.7)$ & $10.59(6.00-14.50)$ & 0.0049 \\
\hline Cumulative time on CART [years] ${ }^{*}$ & $12.43(4.7-21.2)$ & $19.92(12.40-28.00)$ & 0.0021 \\
\hline
\end{tabular}

${ }^{*}$ Median, IQR, $n$ (\%) - absolute number (percentage), other data - arithmetic mean

$H E T$ - heterosexual contacts, IDU - intravenous drug users, MSM - men who have sex with men

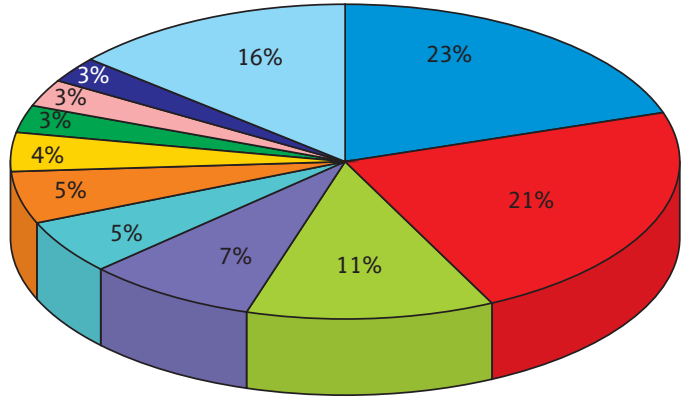

Lipoatrophy of the face, limbs and buttocks

Lipoatrophy of the face, limbs and buttocks + lipoaccumulation of abdomen

$\square$ Lipoaccumulation of abdomen

$\square$ Lipoatrophy of the face and limbs

$\square$ Lipoatrophy of the face and lipoaccumulation of abdomen

$\square$ Lipoatrophy of the face, limbs and buttocks + lipoaccumulation of abdomen and neck

$\square$ Lipoaccumulation of abdomen and neck

Lipoatrophy of the face and limbs + lipoaccumulation of abdomen and neck

$\square$ Lipoatrophy of the face and limbs + lipoaccumulation of abdomen

Lipoatrophy of the face

$\square$ Other combinations

Figure 2. Combinations of dystrophic changes in lipodystrophy syndrome patients

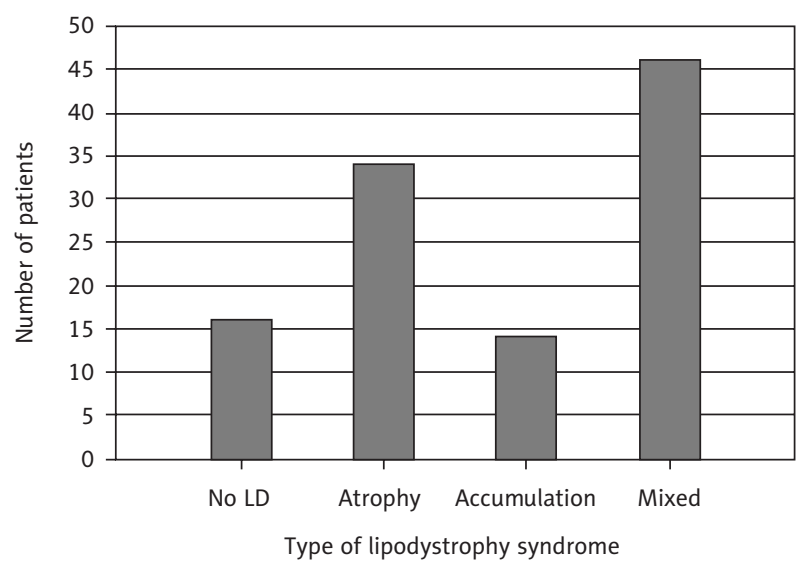

Figure 3. Numbers of patients with various dystrophic changes

group, compared with accumulation and mixed subgroups; it was the highest in the accumulation subgroup in comparison to mixed and no-LS groups. WHR was noticeably higher in the mixed subgroup than in no-LS and atrophy groups. Patients with mixed changes were significantly older and had more advanced atherosclerotic changes (cIMT mean-max), compared with no-LS group. cIMT values and pack-years were of little statistical significance. Metabolic syndrome was observed among the patients with adipose tissue accumulation and with mixed forms. The subgroups of patients with various dystrophic changes did not differ in: occurrence of atherosclerotic plaques, results of labo- 
Table 5. Statistically significant differences in subgroups depending on LS type

\begin{tabular}{|c|c|c|c|c|c|c|}
\hline Feature & $\begin{array}{c}(0) \\
\text { No LS } \\
n=16\end{array}$ & $\begin{array}{c}(1) \\
\text { Atrophy } \\
n=34\end{array}$ & $\begin{array}{c}(2) \\
\text { Accumulation } \\
n=14\end{array}$ & $\begin{array}{c}(3) \\
\text { Mixed } \\
n=46\end{array}$ & $p$-value & Post hoc \\
\hline $\begin{array}{l}\text { Age } \\
\text { (years) }(a, s d)\end{array}$ & $33(26.5-42.0)$ & $40(31.0-48.0)$ & $33.5(32.0-41.0)$ & $41.5(38.0-47.0)$ & 0.015 & 0 vs. $3, p=0.052$ \\
\hline $\mathrm{BMI}^{*}$ & $23.6(20.9-25)$ & $21.1(19.4-23.0)$ & $25.4(24.2-28.1)$ & $23.4(21.6-25.3)$ & 0.0001 & $\begin{array}{c}1 \text { vs. } 2, p=0.0001 \\
1 \text { vs. } 3, p=0.006\end{array}$ \\
\hline Waist $(\mathrm{cm})^{*}$ & $78(73.5-85.5)$ & $78.5(74.0-86.0)$ & $86(81.0-101.0)$ & 85 (80.5-95.0) & 0.0001 & $\begin{array}{l}0 \text { vs. } 3, p=0.023 \\
1 \text { vs. } 3, p=0.003 \\
1 \text { vs. } 2, p=0.042\end{array}$ \\
\hline Hips $(\mathrm{cm})^{\star}$ & $94.5(88.5-1.0)$ & $90(84.0-94.0)$ & $100.5(98.0-103.0)$ & $94(88.0-98.0)$ & 0.0001 & $\begin{array}{l}1 \text { vs. } 2, p=0.0001 \\
2 \text { vs. } 3, p=0.003 \\
1 \text { vs. } 3, p=0.056 \\
0 \text { vs. } 2, p=0.054\end{array}$ \\
\hline WHR* & $0.846(0.79-0.91)$ & $0.882(0.84-0.94)$ & $0.886(0.8-0.93)$ & $0.944(0.88-1.01)$ & 0.001 & $\begin{array}{l}0 \text { vs. } 3, p=0.002 \\
1 \text { vs. } 3, p=0.033\end{array}$ \\
\hline Smokers, $n$ (\%) & $15(93.7)$ & $32(94.1)$ & $12(85.7)$ & 34 (73.9) & 0.06 & \\
\hline $\operatorname{cIMT}(\mathrm{mm})^{*}$ & $0.613(0.54-0.75)$ & $0.657(0.57-0.81)$ & $0.631(0.54-0.82)$ & $0.7(0.61-0.81)$ & 0.099 & \\
\hline $\begin{array}{l}\text { cIMT mean- } \\
\max (\mathrm{mm})^{*}\end{array}$ & $0.859(0.75-1.8)$ & $0.96(0.84-1.26)$ & $0.968(0.83-1.26)$ & $1.062(0.91-1.19)$ & 0.039 & 0 vs. $3, p=0.029$ \\
\hline $\begin{array}{l}\text { Metabolic } \\
\text { syndrome, } n(\%)\end{array}$ & $2(12.5)$ & $0(0)$ & $5(35.7)$ & $15(32.6)$ & 0.001 & $\begin{array}{l}1 \text { vs. } 2, p=0.002 \\
1 \text { vs. } 3, p=0.002\end{array}$ \\
\hline $\begin{array}{l}\text { Time of HIV } \\
\text { infection, years* }\end{array}$ & $4(2.050-8.0)$ & $7(3.0-12.0)$ & $3(1.0-9.0)$ & $11(5.0-17.0)$ & 0.006 & 0 vs. $3, p=0.027$ \\
\hline $\begin{array}{l}\text { Cumulative } \\
\text { NRTI (years)* }\end{array}$ & $2.49(0.2-12.40)$ & $8.54(4.9-12.7)$ & $4.41(3.2-10.7)$ & $11.04(5.7-14.2)$ & 0.03 & 0 vs. $3, p=0.05$ \\
\hline $\begin{array}{l}\text { Cumulative } \\
\text { cART (years)* }\end{array}$ & $6.75(2.3-21.3)$ & $17.15(9.6-21.9)$ & $9.28(6.4-22.5)$ & $20.2(11.2-27.9)$ & 0.045 & 0 vs. $3, p=0.073$ \\
\hline
\end{tabular}

${ }^{*}$ Median, IQR, $n$ (\%) - absolute number (percentage), other data-arithmetic mean, post-hoc analysis

ratory tests (lipid profile, glucose, insulin, CRP, fibrinogen, D-dimers), and in such risk factors as: cardiovascular disease risk factors, hypertension, diabetes or positive family history.

The time of HIV infection, cumulative time of NRTIs and cumulative time on cART were significantly longer in the mixed subgroup than in no-LS group (Table 5). No significant differences were discovered in the mode of HIV transmission and immunological or virological state. The time of antiretroviral treatment and total time of PIs and NNRTIs treatment were similar.

In further analysis of logistic regression cumulative cART and smoking had an influence on the severity of lipodystrophy syndrome (Table 6). In subsequent models, after disregarding cumulative cART and including cumulative NRTIs and PIs treatment, and then NNRTIs treatment, it was discovered that cumulative NRTIs treatment and smoking had an independent influence on severity of lipodystrophy syndrome ( $p=0.004$ and $p=0.0152$, respectively) (Table 6). Adding the current number of CD4+ T-lymphocytes to the model did not change the result and had no impact on the severity of LS.

\section{Discussion}

Prevalence of LS in HIV-infected patients varies from $8 \%$ to $84 \%$ in different studies; it is usually correlated to the characteristics of the research project, inclusion criteria and observation time $[1,10,18,19,22,30-32]$.

In this study, 94 out of 110 patients were diagnosed with LS, which represents $85 \%$ of the study group. This is not an isolated case of such a high percentage of LS diagnosis. Similar results were observed by Rozenbaum et al. (84\%) and by Carr et al. $(83 \%)[14,19]$.

However, some studies indicate a much lower prevalence of LS, e.g. Martinez et al. diagnosed it in $17 \%$ of patients, Mercie et al. - in $26 \%$ of patients [25, 27].

All types of dystrophic changes were observed in our study, with the majority of mixed forms (41.7\%), lipoatrophy (30.9\%) and, least frequently, lipoaccumulation (12.7\%). These results are consistent with the findings of the HIV Outpatient Study, where LS was diagnosed in $49 \%$ of patients, mixed forms were most frequent $(22.7 \%)$ and prevalence of lipoatrophy (13.3\%) and lipoaccumulation (13.2\%) were similar [18]. Different findings were presented by Thiebaut et al. in a French cohort, where mixed forms were least 
Table 6. Influence of various factors on severity of lipodystrophy

\begin{tabular}{|c|c|c|c|c|c|c|c|}
\hline Variable & OR & $95 \% \mathrm{Cl}$ & $p$ & Variable & OR & $95 \% \mathrm{Cl}$ & $p$ \\
\hline \multicolumn{4}{|c|}{ MODEL 1} & \multicolumn{4}{|c|}{ MODEL 2} \\
\hline Age & 1.0479 & $0.9912-1.1078$ & 0.099 & Age & 1.0518 & $0.9936-1.1134$ & 0.08 \\
\hline Sex & 1.4816 & $0.5399-4.0658$ & 0.45 & Sex & 1.6447 & $0.5851-4.6234$ & 0.35 \\
\hline Pack-years & 1.0245 & $0.9908-1.0594$ & 0.16 & Pack-years & 1.0247 & $0.9910-1.0595$ & 0.15 \\
\hline Hypertension & 2.0866 & $0.7542-5.7732$ & 0.16 & Hypertension & 1.9614 & $0.7019-5.4810$ & 0.2 \\
\hline HOMA-IR* & 1.4392 & $0.9025-2.2952$ & 0.13 & HOMA-IR* & 1.3715 & $0.8629-2.1799$ & 0.18 \\
\hline $\mathrm{HCV}$ & 0.4784 & $0.1806-1.2678$ & 0.14 & $\mathrm{HCV}$ & 0.4993 & $0.1868-1.3344$ & 0.17 \\
\hline \multirow[t]{2}{*}{ Cumulative cART } & 1.0571 & $1.0128-1.1033$ & 0.011 & Cumulative NRTI & 1.0856 & $1.0027-1.1754$ & 0.0428 \\
\hline & & & & Cumulative PI & 1.094 & $0.9653-1.2398$ & 0.16 \\
\hline \multicolumn{8}{|c|}{ Stepwise } \\
\hline Variable & OR & $95 \% \mathrm{Cl}$ & $p$ & Variable & OR & $95 \% \mathrm{Cl}$ & $p$ \\
\hline Pack-years & 1.0373 & $1.0066-1.0689$ & 0.0168 & Pack-years & 1.0377 & $1.0072-1.0693$ & 0.0152 \\
\hline Cumulative cART & 1.0628 & $1.0198-1.1076$ & 0.0039 & Cumulative NRTI & 1.1148 & $1.0353-1.2003$ & 0.004 \\
\hline
\end{tabular}

*Homeostatic Model Assessment of Insulin Resistance

frequent (10\%), lipoatrophy was most common (16\%) and isolated lipoaccumulation was observed in $12 \%$ out of $38 \%$ of patients diagnosed with LS [26].

Trevisol et al. observed high frequencies of lipoaccumulation (46\%) and lipoatrophy (53.2\%) in a group where 53.2\% of HIV-infected patients were diagnosed with LS [33].

In the presented cohort, significant differences in anthropometric measurements were observed, depending on the type and severity of LS. Patients with more advanced LS had lower BMI and higher WHR. The higher WHR was a consequence of a significantly lower hip circumference, resulting from adipose tissue loss in this region.

A higher BMI and waist circumference was observed in patients with lipoaccumulation and with mixed forms. Patients with lipoatrophy had a noticeably lower hip circumference. Patients with mixed forms had significantly higher WHR in comparison to no-LS and atrophy subgroups. The relation between dystrophic changes and anthropometric measurements was studied by Thiebaut et al. Among patients receiving cART, the prevalence of lipoatrophy grew with age and was higher in males and in patients with $\mathrm{BMI} \leq 25$. Lipoaccumulation was correlated to higher BMI and WHR; no significant relationship between lipoaccumulation and age has been discovered. The percentage of mixed forms was correlated to older age and higher WHR [26]. However, Alencastro et al. observed a different correlation between dystrophic changes and age or BMI. In their research, patients on antiretroviral therapy were older and had significantly higher BMI. Lipodystrophy and lipohypertrophy were correlated to age and BMI, whereas lipoatrophy was only correlated to BMI, without any significant influence of age [6]. Mercie et al. observed significantly older age of patients diagnosed with LS and noticeably lower BMI and CD4+ T-lymphocyte count in comparison with cART-using patients with no LS [25]. In the ma- jority of findings, LS features are found in patients treated with antiretroviral therapy $[6,7]$.

One of the main inclusion criteria for the present study was antiretroviral treatment. Its significant influence was observed especially in the subgroup of patients with severe LS. The influence of both total and cumulative time of cART on LS types and severity has been discovered. Cumulative protease inhibitors treatment was related to LS severity, but not to LS types. NRTIs medications were correlated to LS development. Cumulative time of NRTIs treatment had influence on severity of lipodystrophy and occurrence of mixed forms. The influence of time of cART on LS and its relationship with various types of lipodystrophy have been observed in numerous clinical studies $[1,7,11,18,26,27]$.

However, Thiebaut et al. did not observe a significant relationship between LS and particular antiretroviral medications, except for the influence of time on cART on LS types and severity of symptoms [26].

In many clinical studies, the influence of various classes of antiretroviral drugs and of specific antiretroviral drugs on LS in HIV-infected patients was observed. Since the introduction of antiretroviral treatment, PIs has been the first class whose side effects have been described as lipodystrophy syndrome. The influence of this class of medications, specific drugs and time of PI treatment on LS development and severity have been widely described $[1,2,6,11,14,27]$.

In one of the first LS studies in 1999, Carr et al., after an over twenty-month long observation, discovered fat distribution disorders in PI-treated patients in comparison to HIV-infected, untreated patients [14]. PIs were closely associated with visceral adipose tissue growth and adverse changes in patients' metabolic profile. Since LS was also observed in patients never treated with PIs, further studies proved the negative influence of other classes of antiret- 
roviral drugs on LS development $[7,8,11,31]$. Peripheral lipoatrophy is mostly associated with some NRTIs [5, 8, $11,34]$. Mallal et al. also found independent influence of NRTIs on LS; moreover, they discovered a correlation between the time of NRTIs treatment, the use of two different medications of this class and the increased risk of lipoatrophy. In their study of an Australian cohort of HIV-infected patients, evident influence of PIs on faster development of NRTI-induced atrophic changes, even in comparison to treatment with two different NRTI drugs, without PI, was observed. They discovered a slow development of lipoatrophy in NRTI-treated patients and progression of atrophic changes when combination therapy of NRTIs and PIs was used [11]. The influence of cART on LS prevalence was also studied by van der Valk et al. In their research, LS was more frequently diagnosed in patients on PIs and NRTIs treatment than in patients on PIs treatment alone [7]. In the present study, more severe LS and mixed forms were observed in patients with a significantly longer documented time of HIV infection. These patients were also older. These observations are consistent with most publications. The correlation between the time of HIV infection, its severity, patients' age and prevalence and severity of dystrophic changes is undisputable $[6,18,27]$. Mercie et al. discovered a visibly lower CD4+ T-lymphocyte count in a group of significantly older patients with LS than in a no-LS group [25]. In the study of 1240 patients, Alencastro et al. observed a correlation between LS and cART treatment with longer time since HIV diagnosis, older age and CD4+ T-lymphocyte count below 350 cells/ $\mu \mathrm{l}[6]$. But we did not find any significant correlation between CD4 Tcell count (nadir and present) and LS severity, probably because of the low number of patients.

The lipid profile of the study group differed significantly from the profile of the control group. In the study group, total cholesterol, LDL and HDL levels were significantly lower, and triglyceride concentration was significantly higher. In comparison with the control group, the LDL cholesterol level was noticeably lower and TG concentration was significantly higher in patients with severe lipodystrophy (LS2). The vast majority of authors describing lipid dysfunction in HIV-infected patients also observe hypertriglyceridemia [1, 25, 26, 30, 35-37]. Mercie et al. also discovered a significantly higher TG concentration in LS patients than in no-LS subgroup [25]. Moreover, Hsue et al. observed a relationship between a high TG concentration and PI treatment [38]. Another metabolic dysfunction frequently observed in HIV-infected patients is a higher total cholesterol level, contrary to the findings of this study $[25,26,30]$.

Mercie et al. confirmed the relation between a high TC level and LS diagnosis [25]. Hsue et al. did not observe significant differences in TC levels between HIV-patients and healthy controls. They have, however, discovered a noticeably lower HDL level in comparison to the control group, which was also observed in other studies and in the research presented here [25, 38]. Mercie et al. demonstrated high total cholesterol and LDL levels, apart from the low HDL level, which is interpreted as a risk factor for atherosclerosis and cardiovascular diseases, especially in patients with LS [25].

\section{Conclusions}

Lipodystrophy syndrome is still observed in the vast majority of HIV-positive patients receiving antiretroviral therapy, especially those older and with longer time of cumulative NRTI and PI treatment. Smoking is an independent risk factor of the severity of adipose tissue redistribution. A great concern is needed to evaluate body composition and risk factors for metabolic changes to prevent their progression and healthy consequences.

\section{Acknowledgment}

This publication is a part of the Project "Wrovasc - Integrated Cardiovascular Centre", co-financed by the European Regional Development Fund, within Innovative Economy Operational Program, 2007-2013, realized in the Regional Specialist Hospital, Research and Development Center in Wroclaw.

\section{Conflict of interest}

The author's declared no potential conflicts of interest with respect to the research, authorship, and/or publication of this article.

\section{References}

1. Chen D, Misra A, Garg A. Clinical review 153: Lipodystrophy in human immunodeficiency virus-infected patients. J Clin Endocrinol Metab 2002; 87: 4845-4856.

2. Carr A, Samaras K, Burton S, et al. A syndrome of peripheral lipodystrophy, hyperlipidemia and insulin resistance due to protease inhibitors. AIDS 1998; 12: F51-F58.

3. Carr A, Samaras K, Chisholm DJ, et al. Pathogenesis of HIV-1 protease inhibitor-associated peripheral lipodystrophy, hyperlipidaemia, and insulin resistance. Lancet 1998; 351: 1881-1883.

4. Agarwal N, Balasubramanyam A. Viral mechanisms of adipose dysfunction: lessons from HIV-1 Vpr. Adipocyte 2014; 4: 55-59.

5. Guaraldi G, Stentarelli C, Zona S, et al. The natural history of HIVassociated lipodystrophy in the changing scenario of HIV infection. HIV Med 2014; 15: 587-594.

6. Alencastro PR, Wolff FH, Oliveira RR, et al. Metabolic syndrome and population attributable risk among HIV/AIDS patients: comparison between NCEP-ATPIII, IDF and AHA/NHLBI definitions. AIDS Res Ther 2012; 9: 29.

7. van der Valk M, Gisolf EH, Reiss P, et al.; Prometheus study group. Increased risk of lipodystrophy when nucleoside analogue reverse transcriptase inhibitors are included with protease inhibitors in the treatment of HIV-1 infection. AIDS 2001; 15: 847-855.

8. Olczak A. Znaczenie zaburzeń metabolicznych podczas terapii antyretrowirusowej HAART. Przegl Epidemiol 2007; 61: 639-646.

9. Sobieszczyk ME, Hoover DR, Anastos K, et al. Prevalence and predictors of metabolic syndrome among HIV-infected and HIVuninfected women in the Women's Interagency HIV Study. J Acquir Immune Defic Syndr 2008; 48: 272-280.

10. Nguyen KA, Peer N, Mills EJ, et al. A Meta-Analysis of the Metabolic Syndrome Prevalence in the Global HIV-Infected Population. PLoS One 2016; 11: e0150970.

11. Malla SA, John M, Moore CB, et al. Contribution of nucleoside analogue reverse transcriptase inhibitors to subcutaneous fat wasting in patients with HIV infection. AIDS 2000; 14: 1309-1316.

12. Bociąga-Jasik M, Polus A, Góralska J, et al. Metabolic complications and selected cytokines in HIV-infected individuals. Pol Arch Med Wewn 2014; 124: 27-35. 
13. Nolis T. Exploring the pathophysiology behind the more common genetic and acquired lipodystrophies. J Hum Genet 2014; 59: 16-23.

14. Carr A, Samaras K, Thorisdottir A, et al. Diagnosis, prediction, and natural course of HIV-1 protease-inhibitor-associated lipodystrophy, hyperlipidaemia, and diabetes mellitus: a cohort study. Lancet 1999; 353: 2093-2099.

15. Espiau M, Yeste D, Noguera-Julian A, et al.; CoRISpe-MetS Working Group. Metabolic Syndrome in Children and Adolescents Living with HIV. Pediatr Infect Dis J 2016; 35: e171-176.

16. Calmy A, Hirschel B, Cooper DA, et al Clinical update: adverse effects of antiretroviral therapy. Lancet 2007; 370: 12-14.

17. Blashill AJ, Goshe BM, Robbins GK, et al. Body image disturbance and health behaviors among sexual minority men living with HIV. Health Psychol 2014; 33: 677-680.

18. Lichtenstein KA, Ward DJ, Moorman AC, et al. Clinical assessment of HIV-associated lipodystrophy in an ambulatory population; HIV Outpatient Study Investigators. AIDS 2001; 15: 1389-1398.

19. Rozenbaum W, Gharakhanian S, Salhi Y, et al. Clinical and laboratory characteristics of lipodystrophy in a French cohort of HIVinfected patients treated with protease inhibitors (Abstract 12). First International Workshop on Adverse Drug Reactions and Lipodystrophy in HIV, San Diego, CA, 1999, p.20.

20. Avotedu K, Ekpebegh C, Longo-Mbenza B, et al. Prevalence of metabolic syndrome assessed by IDF and NCEP ATP 111 criteria and determinants of insulin resistance among HIV patients in the Eastern Cape Province of South Africa. Diabetes Met Syn Clin Res Rev 2010; 4: 210-214.

21. Sheth SH, Larson RJ. The efficacy and safety of insulin-sensitizing drugs in HIV-associated lipodystrophy syndrome: a meta-analysis of randomized trials. BMC Infect Dis 2010; 10: 183 .

22. Samaras K, Wand H, Law M, et al. Prevalence of metabolic syndrome in HIV-infected patients receiving highly active antiretroviral therapy using nternational Diabetes Foundation and Adult Treatment Panel III Criteria: associations with insulin resistance, disturbed body fat compartmentalization, elevated C-reactive protein, and hypoadiponectinemia. Diabetes Care 2007; 30: 113-119.

23. Bindlish S, Presswala LS, Schwartz F. Lipodystrophy: Syndrome of severe insulin resistance. Postgrad Med 2015; 127: 511-516.

24. Guillen MA, Mejia FA, Villena J, et al. Insulin resistance by homeostasis model assessment in HIV-infected patients on highly active antiretroviral therapy: cross-sectional study. Diabetol Metab Syndr 2015; 7: 49.

25. Mercie P, Tchamgoue S, Thiebaut R, et al. Atherogenic lipid profile in HIV-1-infected patients with lipodystrophy syndrome. Eur J Intern Med 2000; 11: 257-263.

26. Thiebaut R, Daucourt V, Mercie P, et al. Lipodystrophy, metabolic disorders and human immunodeficiency virus infection: Aquitaine Cohort, France, 1999. Clin Infect Dis 2000; 31: 482-487.

27. Martinez E, Mocroft A, Garcia-Viejo MA, et al. Risk of lipodystrophy In HIV-1-infected patients treated with protease inhibitors: a prospective kohort study. Lancet 2001; 357: 592-598.

28. Kwiatkowska W, Knysz B, Arczyńska K, et al. Peripheral arterial disease and ankle-brachial index abnormalites in young and middle-aged HIV-positive patients in lower Silesia, Poland. PLoS One 2014; 9: el13857.

29. Kwiatkowska W, Kwiatkowski J, Kawa K. The computerized analyzing system for measurement of the intima-media thickness. Acta MOSIS 1997; 66: 265-270.

30. Rakotoambinina B, Medioni J, Rabian C, et al. Lipodystrophic syndromes and hyperlipidemia in a cohort of HIV-1-infected patients receiving triple combination antiretroviral therapy with a protease inhibitor. J Acquir Immune Defic Syndr 2001; 27: 443-449.

31. Brown TT, Li X, Cole SR, et al. Cumulative exposure to nucleoside analogue reverse transcriptase inhibitors is associated with insulin resistance markers in the Multicenter AIDS Cohort Study. AIDS 2005; 19: 1375-1383.
32. Hadigan C, Meigs JB, Corcoran C, et al. Metabolic abnormalities and cardiovascular disease risk factors in adults with human immunodeficiency virus infection and lipodystrophy. Clin Infect Dis 2001; 32: 130-139.

33. Trevisol FS, Alencastro PR, Ribeiro PAB, et al. Association of physical activity with lipodystrophy syndrome in HIV-infected patients. J AIDS Clinic Res 2012; 3: 177

34. Tebas P, Zhang J, Hafner R, et al. Peripheral and visceral fat changes following a treatment switch to a non-thymidine analogue or a nucleoside-sparing regimen in HIV-infected subjects with peripheral lipoatrophy: results of ACTG A5110. J Antimicrob Chemother 2009; 63: 998-1005.

35. Bednasz C, Luque AE, Zingman BS, et al. Lipid-Lowering Therapy in HIV-Infected Patients: Relationship with Antiretroviral Agents and Impact of Substance-Related Disorders. Curr Vasc Pharmacol 2016; 14: 280-287

36. Patni N, Diaz EG, Cabral MD, et al. Worsening hypertriglyceridemia with oral contraceptive pills in an adolescent with HIVassociated lipodystrophy: a case report and review of the literature. J Pediatr Endocrinol Metab 2014; 27: 1247-1251.

37. Loonam CR, Mullen A. Nutrition and the HIV-associated lipodystrophy syndrome. Nutr Res Rev 2012; 25: 267-287.

38. Hsue PY, Lo JC, Franklin A, et al. Progression of atherosclerosis as assessed by carotid Intima-Media Thickness in patients with HIV infection. Circulation 2004; 109: 1603-1608. 